\title{
Antimicrobial consumption in five adult intensive care units: a 33-month surveillance study
}

\author{
Hanan H. Balkhy ${ }^{1,2,3^{*}}$, Aiman El-Saed ${ }^{1,3,4}$, Ashraf El-Metwally', Yaseen M. Arabi ${ }^{1,2,5}$, Sameera M. Aljohany ${ }^{1,6}$, \\ Muayed Al Zaibag ${ }^{7}$, Salim Baharoon ${ }^{1,8}$ and Adel F. Alothman ${ }^{1,8}$
}

\begin{abstract}
Background: Estimating the baseline antimicrobial consumption is extremely important to monitor the impact of antimicrobial stewardship activities that aim to reduce the burden and cost of antimicrobial consumption.

Objectives: To quantify service-specific antimicrobial consumption using different metrics.

Methods: A surveillance study was conducted at King Abdulaziz Medical City, Riyadh, Saudi Arabia, between October 2012 and June 2015 in five adult intensive care units (ICUs). Consumption data were collected manually on a daily basis by infection control practitioners. Data were presented as defined daily dose (DDD), days of therapy (DOT) per 1000 patient days, and frequency of daily consumption.
\end{abstract}

Results: A total of 43,970 DDDs and 46,940 DOTs were monitored during 54,116 patient-days. For the most frequently consumed antimicrobials, the consumption of carbapenems, piperacillin/tazobactam, vancomycin, and colistin (respectively) in all ICUs combined were 255.9, 134.3, 98.2, and 13.6 DDDs per 1000 patient-days and 235.7, 145.9, 129.5, and 117.5 DOTs per 1000 patient-days. For the frequency of daily consumption, carbapenems were the most frequently consumed antimicrobial group in medical/surgical, burn, and step-down ICUs while piperacillin/tazobactam was the most frequently consumed antimicrobial in neuro-surgical and cardio-thoracic ICUs.

Conclusion: High consumption of broad-spectrum antimicrobial agents such as meropenem and piperacillin/ tazobactam is observed in multiple ICUs in a tertiary care hospital. Meropenem consumption is considerably higher than similar ICUs internationally. Future studies focusing on concurrent monitoring of antimicrobial resistance and identifying patient and physician characteristics associated with specific prescription patterns may help in improving judicious antimicrobial consumption.

Keywords: Antimicrobial agents, Antimicrobial resistance, Consumption, Defined daily dose, Days of therapy, Saudi Arabia

\section{Background}

Antimicrobials are the most frequently misused therapeutic drugs worldwide [1]. Antimicrobial- associated adverse effects are frequently mild, but sometimes can be life-threatening and require emergency care $[2,3]$.

\footnotetext{
*Correspondence: balkhyh@hotmail.com; balkhyh@ngha.med.sa

${ }^{1}$ King Saud bin Abdulaziz University for Health Sciences, Riyadh, Kingdom of Saudi Arabia

${ }^{2}$ Infectious Diseases, King Abdullah International Medical Research Center,

Riyadh, Kingdom of Saudi Arabia

Full list of author information is available at the end of the article
}

The widespread consumption of antimicrobial agents especially broad-spectrum ones may reflect the physician's concern and the need for effective therapy for severely ill patients. Additionally, it cannot be dissociated from the worldwide problem of antimicrobial resistance (AMR) [4-6]. Ecological data have confirmed higher AMR in countries with higher antimicrobial consumption [7]. The global emergence of AMR has increased patient morbidity, mortality, and health care costs. [8]. With the global concern of rising AMR, the World Health Organization (WHO) has established a five-pillar

(c) The Author(s). 2018 Open Access This article is distributed under the terms of the Creative Commons Attribution 4.0 International License (http://creativecommons.org/licenses/by/4.0/), which permits unrestricted use, distribution, and reproduction in any medium, provided you give appropriate credit to the original author(s) and the source, provide a link to the Creative Commons license, and indicate if changes were made. The Creative Commons Public Domain Dedication waiver (http://creativecommons.org/publicdomain/zero/1.0/) applies to the data made available in this article, unless otherwise stated. 
global action plan to be adopted by member states to address the AMR challenge at the national level [9]. Increasing knowledge of antimicrobial consumption and resistance through surveillance is one of those five pillars. Similarly, the strategic plan for combating AMR in Gulf Cooperation Council (GCC) States called for monitoring the trends of the antimicrobial consumption using different metrics [10].

As stewardship programs can be cost-effective in reducing unnecessary consumption of restricted and non-restricted antimicrobials [11, 12], King Abdulaziz Medical City-Riyadh (KAMC-R) established a stepwise stewardship program and created guidelines for antimicrobial consumption. However, data on the amount of antimicrobial consumption at a tertiary care setting is largely lacking, both locally and nationally $[14,15]$. Estimating the baseline antimicrobial consumption may serve multiple stewardship purposes; to identify hospital units/wards of highest consumption, to monitor the impact for future interventions, and to feedback prescribing physicians with the prescription patterns. The latter by itself has been proven very beneficial in reducing antimicrobial consumption [13]. Therefore, the objective of this study was to quantify service-specific antimicrobial consumption using different metrics in intensive care settings.

\section{Methods}

\section{Setting}

The study was conducted at KAMC-R, Ministry of National Guard Health Affairs (MNGHA) in Saudi Arabia. This healthcare system is governmentally funded and provides healthcare services for about 750,000 Saudi National Guard soldiers, employees, and their families. KAMC-R is a 1000 -bed tertiary care facility with 11 different intensive care units (ICUs, a total of 140 beds) and 36 wards covering almost all specialties. The five adult ICUs included in this study were medical/surgical, neurosurgical, burn, cardiothoracic, and step-down ICUs. Together, they have 60 beds and provide care for approximately 1800 patients per year, staying for approximately 20,000 patient-days per year. The overall bed utilization in the included ICUs was $91 \%$ and the average length of stay was 11 days.

The antimicrobial committee at KAMC- $\mathrm{R}$ is a multi-disciplinary committee that reviews and approves antimicrobial agents for the hospital formulary, develops and updates the guidelines for antimicrobial consumption, in addition to establishing the antimicrobial stewardship team. However, at the time of the production of this manuscript, regular stewardship rounds were not initiated yet.

\section{Population}

The five operational adult ICUs at KAMC-R at the start of the study were included. For the numerator, all adult patients admitted to one of the included ICUs during the study period and received at least one dose of one of the included antimicrobials. For the denominator data, all adult patients admitted to one of the included ICUs during the study period irrespective of antimicrobial consumption. Exclusion criteria included age $<18$ years, consumption of antimicrobials not included in the study, and consumption of antimicrobial by a route other than parenteral or oral routes.

\section{Study design}

A surveillance study was conducted at KAMC-R, Saudi Arabia, between October 2012 and June 2015. The study was approved by the ethical committee of King Abdullah International Medical Research Center (KAIMRC) and was funded by KAIMRC.

\section{Outcome definition}

Defined daily dose (DDD, expressed in grams) was defined as the average maintenance dose per day for a drug used for its main indication in a $70 \mathrm{~kg}$ adult, as per the WHO and Anatomical Therapeutic Chemical (ATC) definition of a specific DDD [16]. Days of therapy (DOT) were defined as the sum of days (including admission and discharge days) for which any amount of a specific antimicrobial agent was administered to individual patients [17]. Patient days were calculated as the number of patients who were present for any portion of each day (including admission and discharge days) of a calendar month at a specific ICU. Included antimicrobials were aminoglycosides (amikacin or gentamicin), carbapenems (imipenem or meropenem), cephalosporins (ceftriaxone, cefotaxime, ceftazidime, or cefepime), fluoroquinolones (ciprofloxacin or norfloxacin), piptazocin (piperacillin/tazobactam), vancomycin, tigecycline, colistin, caspofungin, and amphotericin B. The frequency of daily antimicrobial consumption was defined as the number of times a specific antimicrobial was consumed out of all times any antimicrobial was consumed.

\section{Data collection}

Data of antimicrobial consumption were collected prospectively on a daily basis by infection control practitioners, using specially created data entry forms. The following variables were recorded; age, gender, ICU type, name, dose, frequency, and route of antimicrobial consumption. The antimicrobial event was recorded (as a new row in the data file) once a patient received at least one dose of one of the included antimicrobials during a certain day. Each antimicrobial event (row) was considered as one day of therapy. The same patient can contribute to more than one antimicrobial event on the same day if he/she received more than one antimicrobial agent on the same day. The same patient can contribute 
to more than one specific antimicrobial event during the same admission if he/she received the same antimicrobial for more than one day.

\section{Statistical methods}

Continuous variables were presented as means, standard deviations, and sums. Categorical variables were presented as frequencies and percentages. The amount of DDD consumption was calculated separately for each antimicrobial by dividing the total amount of consumption in grams by antimicrobial-specific average DDD. The amounts of antimicrobial consumption were presented as DDD and DOT per 1000 patient days. Mann-Whitney test and Kruskal Wallis test were used to test significant differences in DDD and DOT by gender and age groups, respectively. All $P$-values were two-tailed. P-value $<0.05$ was considered as significant. SPSS (Version 23.0. Armonk, NY: IBM Corp) was used for all statistical analyses.

\section{Results}

Over the 33 months of the study, 43,970 DDDs and 46,940 DOTs were monitored during 4919 admissions contributing to 54,116 patient-days. As shown in Table 1, the majority of the antimicrobial consumption (as sum of DOTs in all ICUs) was observed in males (57.9\%), those older than 65 years of age (46.6\%), and those admitted to medical/surgical ICU (49.3\%) or step-down ICU (24.3\%). On average, patients consumed $0.94 \pm 0.91$ DDDs of one or more antimicrobial agent per day. On average, patients consumed 9.5 DOTs of one or more antimicrobial agents per admission (average 11 days). Heavy antimicrobial consumption (as DOTs per admission) was observed in patients admitted to step-down ICU (18.3), followed by medical/surgical (14.3), burn (9.8), neurosurgical (7.0), and lastly cardiothoracic (2.0) ICUs. The top 5 consumed antimicrobial agents (as sum of DOTs in all ICUs) included meropenem (21.4\%), piperacillin/tazobactam (16.8\%), vancomycin (14.9\%), colistin (13.5\%), and caspofungin (8.0\%). The least frequently consumed antimicrobial agents (as the sum of DOTs in all ICUs) included cefotaxime (0.2\%), amphotericin B $(0.8 \%)$, cefepime $(1.2 \%)$, amikacin $(1.3 \%)$, and ceftazidime (1.3\%). Almost all (98.7\%) antimicrobial consumption was through intravenous route.

As shown in Fig. 1, there was considerable variability in the trend of antimicrobial consumption during the study irrespective of the metrics used. It reached maximum towards the end of 2014 and beginning of 2015 and minimum during the second quarter of 2014. However, the antimicrobial consumption during the first and last quarters of the study was very similar.

Table 2 shows ICU-specific antimicrobial consumption in DDDs per patient-days. For the most frequently consumed antimicrobials, the average amount of carbapenems, piperacillin/tazobactam, and vancomycin in all ICUs combined were 255.9, 134.3, and 98.2 DDDs per 1000 patient-days, respectively. Carbapenems were the most frequently consumed antimicrobial group in all ICUs except cardiothoracic ICU. Piperacillin/tazobactam was the most frequently consumed antimicrobial in cardiothoracic ICU and was preceded only carbapenems in three out of the other four ICUs. Vancomycin was the third to fifth frequently consumed antimicrobials in different ICUs. For the least frequently consumed antimicrobials, the average amount of consumption of colistin, aminoglycosides, and tigecycline in all ICUs combined were 13.6, 19.8, and 23.2 DDDs per 1000 patient-days, respectively. There was no amphotericin B consumption in cardiothoracic ICU.

Table 3 shows ICU-specific antimicrobial consumption in DOTs per patient-days. For the most frequently consumed antimicrobials, the average amount of consumption of carbapenems, piperacillin/tazobactam, vancomycin, and colistin in all ICUs combined were 235.7, 145.9, 129.5, and 117.5 DOTs per 1000 patient-days, respectively. As shown in Table 3 (duration of consumption as DOTs) and Fig. 2, (DOTs-dependent frequency of daily consumption), carbapenems were the most frequently consumed antimicrobial group in medical/surgical, burn, and step-down ICUs while piperacillin/tazobactam was the most frequently consumed antimicrobial in neurosurgical and cardiothoracic ICUs. Colistin was the second most frequently consumed antimicrobial in burn and step-down ICUs while vancomycin was the third most frequently consumed antimicrobial in all ICUs except burn ICU. For the least frequently consumed antimicrobials, the average amount of consumption of amphotericin B and tigecycline in all ICUs combined were 7.2 and 21.5 DOTs per 1000 patient-days, respectively. In all ICUs, the order of the amount (Table 2) and duration (Table 3) of antimicrobial consumption was identical. The consumption data in Tables 2 and 3 were additionally presented as DDDs and DOTs per 100 admissions in supplemental data.

\section{Discussion}

ICU-specific antimicrobial consumptions at a major tertiary care hospital were presented in this report using multiple metrics; including DDD, DOT, and the frequency of daily consumption. The calculation of different metrics was essential to improve the clinical and benchmarking usability of this data. For example, it has been shown that the choice of indicator for the surveillance of antimicrobial consumption is critical to evaluate the impact of any stewardship program $[15,18]$ and to enhance the ability to predict future AMR [19]. Additionally, complementary and sometimes conflicting findings of the impact of antimicrobial stewardship have been reported based on whether DDDs versus DOTs are calculated $[15,18,20]$. 
Table 1 Overall antimicrobial consumption using different metrics by the patient demographics, ICU type, and antimicrobial type

\begin{tabular}{|c|c|c|c|c|c|c|c|}
\hline & \multicolumn{2}{|c|}{ Average consumption per day } & \multicolumn{4}{|c|}{ Sum of consumption during the study } & \multirow{2}{*}{$\begin{array}{l}\text { Average } \\
\text { DOT per } \\
\text { admission }\end{array}$} \\
\hline & Grams (mean $\pm \mathrm{SD}$ ) & $\overline{\mathrm{DDD}}($ mean $\pm \mathrm{SD})$ & $\begin{array}{l}\text { DDD } \\
\text { (Sum) }\end{array}$ & DDD (\%) & $\begin{array}{l}\text { DOT } \\
\text { (Sum) }\end{array}$ & $\overline{\mathrm{DOT}}(\%)$ & \\
\hline Overall & $3.23 \pm 4.82$ & $0.94 \pm 0.91$ & $43,970.1$ & $100.0 \%$ & 46,940 & $100.0 \%$ & 9.5 \\
\hline \multicolumn{8}{|l|}{ Age } \\
\hline $19-45$ & $3.79 \pm 5.44$ & $1.08 \pm 1.01$ & $12,706.5$ & $28.9 \%$ & 11,802 & $25.1 \%$ & \\
\hline $46-65$ & $3.27 \pm 4.83$ & $0.93 \pm 0.9$ & $12,396.3$ & $28.2 \%$ & 13,277 & $28.3 \%$ & \\
\hline$>65$ & $2.9 \pm 4.4$ & $0.86 \pm 0.85$ & $18,867.3$ & $42.9 \%$ & 21,861 & $46.6 \%$ & \\
\hline \multicolumn{8}{|l|}{ Gender } \\
\hline Male & $3.45 \pm 5.02$ & $0.95 \pm 0.88$ & $25,725.8$ & $58.5 \%$ & 27,188 & $57.9 \%$ & \\
\hline Female & $2.92 \pm 4.51$ & $0.92 \pm 0.95$ & $18,238.0$ & $41.5 \%$ & 19,743 & $42.1 \%$ & \\
\hline \multicolumn{8}{|l|}{ Type of ICU } \\
\hline Medical/surgical & $2.86 \pm 4.42$ & $0.91 \pm 0.9$ & $20,981.9$ & $47.7 \%$ & 23,150 & $49.3 \%$ & 14.3 \\
\hline Neurosurgical & $5.31 \pm 6.25$ & $1.14 \pm 0.8$ & 6285.9 & $14.3 \%$ & 5504 & $11.7 \%$ & 7.0 \\
\hline Burn & $3.36 \pm 5.14$ & $0.95 \pm 0.75$ & 3632.7 & $8.3 \%$ & 3820 & $8.1 \%$ & 9.8 \\
\hline Cardiothoracic & $5.17 \pm 5.87$ & $0.93 \pm 0.62$ & 2823.4 & $6.4 \%$ & 3050 & $6.5 \%$ & 2.0 \\
\hline Step-down & $2.41 \pm 3.84$ & $0.9 \pm 1.07$ & $10,246.3$ & $23.3 \%$ & 11,416 & $24.3 \%$ & 18.3 \\
\hline \multicolumn{8}{|l|}{ Antimicrobials } \\
\hline Amikacin & $0.63 \pm 0.38$ & $0.63 \pm 0.38$ & 385.1 & $0.9 \%$ & 607 & $1.3 \%$ & \\
\hline Gentamicin & $0.19 \pm 0.13$ & $0.8 \pm 0.53$ & 684.5 & $1.6 \%$ & 851 & $1.8 \%$ & \\
\hline Imipenem & $1.53 \pm 0.62$ & $0.77 \pm 0.31$ & 2079.1 & $4.7 \%$ & 2710 & $5.8 \%$ & \\
\hline Meropenem & $2.34 \pm 1.02$ & $1.17 \pm 0.51$ & $11,770.4$ & $26.8 \%$ & 10,047 & $21.4 \%$ & \\
\hline Ceftriaxone & $2.02 \pm 1.11$ & $1.01 \pm 0.55$ & 1155.5 & $2.6 \%$ & 1142 & $2.4 \%$ & \\
\hline Cefotaxime & $2.89 \pm 0.49$ & $0.72 \pm 0.12$ & 69.4 & $0.2 \%$ & 96 & $0.2 \%$ & \\
\hline Ceftazidime & $3.14 \pm 1.81$ & $0.78 \pm 0.45$ & 495.0 & $1.1 \%$ & 631 & $1.3 \%$ & \\
\hline Cefepime & $2.92 \pm 1.53$ & $1.46 \pm 0.77$ & 856.2 & $1.9 \%$ & 586 & $1.2 \%$ & \\
\hline Ciprofloxacin, IV & $0.72 \pm 0.34$ & $1.44 \pm 0.67$ & 3974.2 & $9.0 \%$ & 2760 & $5.9 \%$ & \\
\hline Ciprofloxacin, oral & $0.76 \pm 0.3$ & $0.76 \pm 0.3$ & 78.4 & $0.2 \%$ & 103 & $0.2 \%$ & \\
\hline Norfloxacin, IV & $0.45 \pm 0.46$ & $0.57 \pm 0.71$ & 463.6 & $1.1 \%$ & 810 & $1.7 \%$ & \\
\hline Norfloxacin, oral & $0.43 \pm 0.14$ & $0.54 \pm 0.17$ & 19.5 & $0.0 \%$ & 36 & $0.1 \%$ & \\
\hline Piperacillin/ Tazobactam & $12.89 \pm 4.33$ & $0.92 \pm 0.31$ & 7270.2 & $16.5 \%$ & 7896 & $16.8 \%$ & \\
\hline Vancomycin, IV & $1.46 \pm 0.86$ & $0.73 \pm 0.43$ & 4715.5 & $10.7 \%$ & 6476 & $13.8 \%$ & \\
\hline Vancomycin, oral & $1.12 \pm 0.51$ & $1.12 \pm 0.51$ & 596.7 & $1.4 \%$ & 533 & $1.1 \%$ & \\
\hline Tigecycline & $0.11 \pm 0.05$ & $1.08 \pm 0.52$ & 1255.5 & $2.9 \%$ & 1163 & $2.5 \%$ & \\
\hline Colistin & $0.35 \pm 0.18$ & $0.12 \pm 0.06$ & 738.3 & $1.7 \%$ & 6360 & $13.5 \%$ & \\
\hline Caspofungin & $0.05 \pm 0.02$ & $1.1 \pm 0.56$ & 4125.5 & $9.4 \%$ & 3742 & $8.0 \%$ & \\
\hline Amphotericin B & $0.29 \pm 0.08$ & $8.28 \pm 2.28$ & 3237.6 & $7.4 \%$ & 391 & $0.8 \%$ & \\
\hline \multicolumn{8}{|l|}{ Route } \\
\hline Intravenous & $3.25 \pm 4.84$ & $0.94 \pm 0.91$ & $43,329.1$ & $98.5 \%$ & 46,311 & $98.7 \%$ & \\
\hline Oral & $1.25 \pm 1.75$ & $1.02 \pm 0.53$ & 641.1 & $1.5 \%$ & 629 & $1.3 \%$ & \\
\hline
\end{tabular}

This is further complicated by the main stewardship target; the length of stay, number of patients receiving treatment, or duration of treatment $[15,18,20]$. Moreover, DDDs and DOTs are theoretically reflecting different aspects of antimicrobial consumption [21].
The main finding of this study was the high consumption of broad-spectrum antimicrobial agents, specifically carbapenems and piperacillin/tazobactam irrespective of the metrics used. Unfortunately, this study cannot determine the magnitude of inappropriate consumption in 


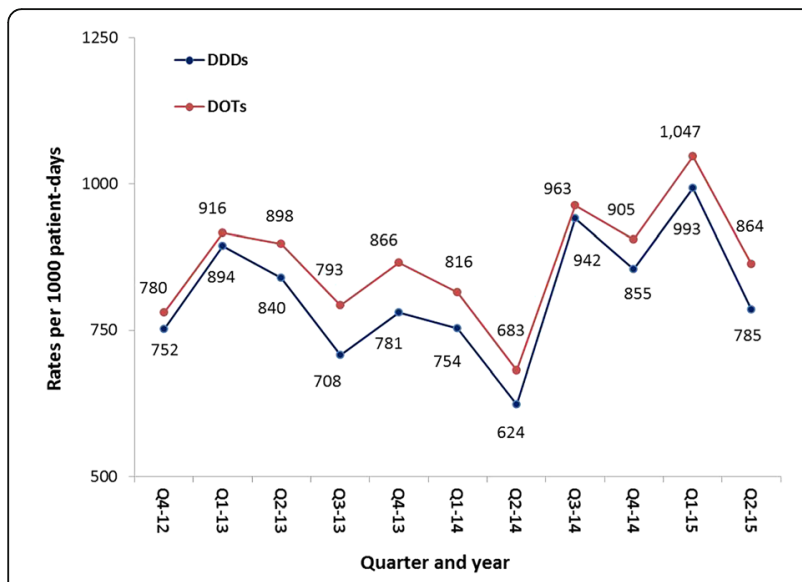

Fig. 1 Trends of overall antimicrobial consumption in all adult ICUs, KAMC-R, 2012-2015 the above broad-spectrum antimicrobials. Nevertheless, it has been reported that between 14 and $79 \%$ of international antibiotic consumption to treat severe infections in hospitals are inappropriate [22]. Similarly, a recent local study reported that $66 \%$ of the consumption of carbapenems and piperacillin/tazobactam in a surgical ward at a tertiary care hospital was either unjustified by culture-test result or done without culture [23]. These rates highlight clinician's inclination to prescribe broad-spectrum agents. Consistent with current findings, several reports from this hospital $[24,25]$ and other hospitals in GCC states [26, 27] identified the emergence and/or high burden of carbapenem-resistant Enterobacteriaceae and carbapenem-resistant Acinetobacter. Infections caused by these resistant pathogens are highly fatal and need poly-antimicrobial therapy including carbapenems [28].

Table 2 ICU-specific antimicrobial consumption in DDDs, KAMC-R,2012-2015

\begin{tabular}{|c|c|c|c|c|c|c|}
\hline & Medical/ surgical & Neuro-surgical & Burn & Cardio-thoracic & Step-down & Total \\
\hline \multicolumn{7}{|l|}{ Number of DDDs } \\
\hline Aminoglycosides & 449.0 & 161.4 & 84.3 & 24.6 & 350.2 & 1069.5 \\
\hline Carbapenems & 6890.1 & 1886.4 & 1102.5 & 772.0 & 3198.6 & $13,849.5$ \\
\hline Cephalosporins & 1278.8 & 610.2 & 158.3 & 52.2 & 476.7 & 2576.1 \\
\hline Fluoroquinolones & 1822.0 & 635.0 & 376.5 & 395.4 & 1306.8 & 4535.6 \\
\hline Piperacillin/Tazobactam & 3044.2 & 1528.0 & 605.8 & 929.9 & 1162.4 & 7270.2 \\
\hline Vancomycin & 2362.2 & 1030.5 & 513.4 & 388.0 & 1018.1 & 5312.2 \\
\hline Tigecycline & 562.5 & 8.5 & 324.0 & 52.5 & 308.0 & 1255.5 \\
\hline Colistin & 305.6 & 93.5 & 138.1 & 21.4 & 179.8 & 738.3 \\
\hline Caspofungin & 2572.7 & 195.4 & 179.0 & 187.4 & 991.0 & 4125.5 \\
\hline Amphotericin B & 1694.9 & 137.1 & 150.9 & 0.0 & 1254.7 & 3237.6 \\
\hline Total & $20,981.9$ & 6285.9 & 3632.7 & 2823.4 & $10,246.3$ & $43,970.1$ \\
\hline \multicolumn{7}{|l|}{ Denominator } \\
\hline Patient days & 19,105 & 7288 & 6759 & 7105 & 13,859 & 54,116 \\
\hline Admissions & 1620 & 786 & 391 & 1499 & 623 & 4919 \\
\hline Average length of stay & 11.8 & 9.3 & 17.3 & 4.7 & 22.2 & 11.0 \\
\hline \multicolumn{7}{|l|}{ Rates per 1000 patient-days } \\
\hline Aminoglycosides & 23.5 & 22.1 & 12.5 & 3.5 & 25.3 & 19.8 \\
\hline Carbapenems & 360.6 & 258.8 & 163.1 & 108.7 & 230.8 & 255.9 \\
\hline Cephalosporins & 66.9 & 83.7 & 23.4 & 7.4 & 34.4 & 47.6 \\
\hline Fluoroquinolones & 95.4 & 87.1 & 55.7 & 55.7 & 94.3 & 83.8 \\
\hline Piperacillin/Tazobactam & 159.3 & 209.7 & 89.6 & 130.9 & 83.9 & 134.3 \\
\hline Vancomycin & 123.6 & 141.4 & 76.0 & 54.6 & 73.5 & 98.2 \\
\hline Tigecycline & 29.4 & 1.2 & 47.9 & 7.4 & 22.2 & 23.2 \\
\hline Colistin & 16.0 & 12.8 & 20.4 & 3.0 & 13.0 & 13.6 \\
\hline Caspofungin & 134.7 & 26.8 & 26.5 & 26.4 & 71.5 & 76.2 \\
\hline Amphotericin B & 88.7 & 18.8 & 22.3 & 0.0 & 90.5 & 59.8 \\
\hline Total & 1098.2 & 862.5 & 537.5 & 397.4 & 739.3 & 812.5 \\
\hline
\end{tabular}


Table 3 ICU-specific antimicrobial consumption in DOTs, KAMC-R, 2012-2015

\begin{tabular}{|c|c|c|c|c|c|c|}
\hline & Medical/ surgical & Neuro-surgical & Burn & Cardio-thoracic & Step-down & Total \\
\hline \multicolumn{7}{|l|}{ Number of DOTs } \\
\hline Aminoglycosides & 683 & 146 & 97 & 55 & 477 & 1458 \\
\hline Carbapenems & 6609 & 1302 & 960 & 725 & 3161 & 12,757 \\
\hline Cephalosporins & 1216 & 480 & 141 & 76 & 542 & 2455 \\
\hline Fluoroquinolones & 1677 & 399 & 209 & 255 & 1169 & 3709 \\
\hline Piperacillin/Tazobactam & 3473 & 1387 & 574 & 1018 & 1444 & 7896 \\
\hline Vancomycin & 3438 & 944 & 518 & 539 & 1570 & 7009 \\
\hline Tigecycline & 512 & 8 & 294 & 53 & 296 & 1163 \\
\hline Colistin & 3002 & 642 & 840 & 183 & 1693 & 6360 \\
\hline Caspofungin & 2322 & 183 & 167 & 146 & 924 & 3742 \\
\hline Amphotericin B & 218 & 13 & 20 & 0 & 140 & 391 \\
\hline Total & 23,150 & 5504 & 3820 & 3050 & 11,416 & 46,940 \\
\hline \multicolumn{7}{|l|}{ Rates per 1000 patient-days } \\
\hline Aminoglycosides & 35.7 & 20.0 & 14.4 & 7.7 & 34.4 & 26.9 \\
\hline Carbapenems & 345.9 & 178.6 & 142.0 & 102.0 & 228.1 & 235.7 \\
\hline Cephalosporins & 63.6 & 65.9 & 20.9 & 10.7 & 39.1 & 45.4 \\
\hline Fluoroquinolones & 87.8 & 54.7 & 30.9 & 35.9 & 84.3 & 68.5 \\
\hline Piperacillin/Tazobactam & 181.8 & 190.3 & 84.9 & 143.3 & 104.2 & 145.9 \\
\hline Vancomycin & 180.0 & 129.5 & 76.6 & 75.9 & 113.3 & 129.5 \\
\hline Tigecycline & 26.8 & 1.1 & 43.5 & 7.5 & 21.4 & 21.5 \\
\hline Colistin & 157.1 & 88.1 & 124.3 & 25.8 & 122.2 & 117.5 \\
\hline Caspofungin & 121.5 & 25.1 & 24.7 & 20.5 & 66.7 & 69.1 \\
\hline Amphotericin B & 11.4 & 1.8 & 3.0 & 0.0 & 10.1 & 7.2 \\
\hline Total & 1211.7 & 755.2 & 565.2 & 429.3 & 823.7 & 867.4 \\
\hline
\end{tabular}

Comparison of the consumption rates from this study with local data is impossible or at least difficult. Previous data quantifying antimicrobial consumption at healthcare settings in Saudi Arabia are very limited [14, 15]. For example, none of the published reports have used a prospective design, stratified the consumption by service/location, or used a comprehensive list of antimicrobial groups as shown in this report. On the other hand, the consumption of carbapenems in this study was considerably higher than the rates reported by several reports around the world. For example, it was 255.9 DDDs per 1000 patient-days in current ICUs compared with 36.9 in French ICUs [29], 37.8 in the US National Nosocomial Infections Surveillance (NNIS) medical-surgical ICUs [30], 81.4 in German ICUs [31], 90.0 in the International Nosocomial Infection Control Consortium (INICC) ICUs [32], 58-143 in Swedish ICUs [33], 196.5 in Italian ICUs [34], and 257.1 in Australian \& New Zealand ICUs [35].

Unlike carbapenems, the consumption of piperacillin/ tazobactam and vancomycin in this study was more comparable to rates reported by above international reports. For example, the consumption of piperacillin/ tazobactam in this study was 134.3 DDDs per 1000 patient-days which was similar to Australian \& New Zealand ICUs (124.7) [35], higher than NNIS, INICC, and France ICUs (47.2-75.5) [29, 30, 32], and lower than Italian and German ICUs (277.2-412.9) [31, 34]. Similarly, the consumption of vancomycin in this study was 98.2 DDDs per 1000 patient-days which was higher than NNIS, INICC, and German ICUs (36.7-91.9) [30-32] but lower than Italian and Australian \& New Zealand ICUs (146.9-191.8) [34, 35].

As most of the DOT-based international reports of antimicrobial consumption were derived from whole hospital data [21,36] or pediatric/neonatal populations $[37,38]$, comparing the current ICU-specific DOT rates is challenging. Nevertheless, this study had slightly higher carbapenems (235.7 versus 196.3) but lower piperacillin/tazobactam (145.9 versus 296.3) and vancomycin (129.5 versus 187.2) compared with a study done in an adult ICU in Canada [39]. Fairly similar to this study, piperacillin/tazobactam and/or carbapenems were among the most frequently consumed broad-spectrum antimicrobial agents in Canadian, Australian, and New Zealand ICUs [35, 39]. On the other hand, the majority 


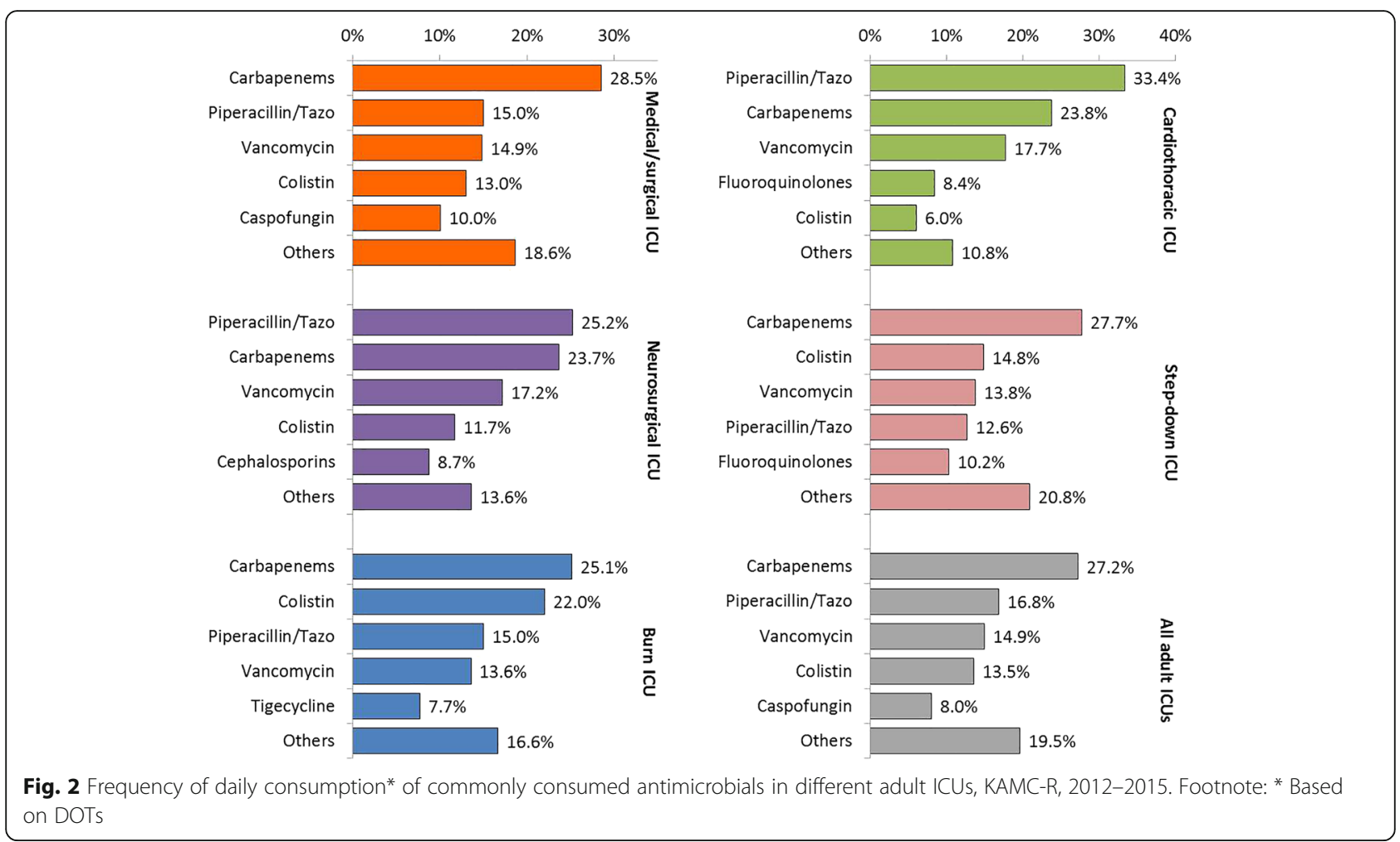

of international studies show that penicillins [29-31, 34] or cephalosporins $[32,33,39]$ are the most frequently consumed antimicrobials in adult ICUs. They represented $30-50 \%$ and $26-37 \%$ of all antimicrobial consumption in these studies compared with only 16.8 and $5.2 \%$ in the current ICUs, respectively.

A major limitation of this study was the inability to address the concurrent appropriateness of antimicrobial consumption. Additionally, the study only targeted antimicrobials frequently consumed in the selected ICU settings, the study does not include less frequently consumed antimicrobials nor those initiated before transfer to the ICU. The target population was National Guard soldiers, employees, and their families at a tertiary care setting. Therefore, interpretation and comparisons of the current findings should be done accordingly. Finally, the study was not designed to take in consideration variations among ICUs in patient mix or predominant bacterial pathogens and their susceptibility patterns. Nevertheless, using the current data to monitor the long-term impacts of different interventions of an antimicrobial stewardship program can potentially help to improve the current prescription practices, reduce cost, and avoid side effects.

\section{Conclusion}

Despite the presence of local written guidelines for antibiotic consumption and the availability of accessible microbiology services, the current finding showed high consumption of broad-spectrum antimicrobial agents such as meropenem and piperacillin/tazobactam in multiple ICUs in a tertiary care hospital. Meropenem consumption was higher than similar ICUs internationally. The findings highlight the urgent need for an effective antimicrobial stewardship program. The GCC Center for infection control has identified AMR as a major threat, and this study represents one of many proposed efforts assisting in mitigating the emergence of AMR in the region [10]. Surveillance and benchmarking of antimicrobial consumption and providing feedback to stakeholders, specifically prescribing physicians can reduce the amount of antimicrobial consumption and probably resistance [13, 40]. Future studies focusing on concurrent monitoring of antimicrobial resistance and identifying patient and physician characteristics associated with specific prescription patterns may help in improving judicious antimicrobial consumption.

\section{Acknowledgments}

We thank the infection control practitioners from the infection prevention and control program, KAMC-R, for the collection of antimicrobial surveillance forms. We thank Ms. Irma Trofeo for the data entry. We thank Mrs. Brittany Lucas for the English editing.

Funding

No funding to declare.

Availability of data and materials

The datasets used and/or analyzed during the current study are available from the corresponding author on reasonable request. 


\section{Authors' contributions}

Drs Balkhy, El-Saed, and Alothman conceptualized and designed the study, drafted the initial manuscript, and reviewed and revised the manuscript. Drs El-Saed, El-Metwally, and Aljohany designed the data collection instruments, collected data, carried out the initial analyses, and reviewed and revised the manuscript. Drs Arabi, Al Zaibag, and Baharoon conceptualized and designed the study, coordinated and supervised data collection, and critically reviewed the manuscript for important intellectual content. All authors approved the final manuscript as submitted and agree to be accountable for all aspects of the work.

\section{Ethics approval and consent to participate}

Not applicable.

\section{Consent for publication}

Not applicable.

\section{Competing interests}

The authors declare that they have no competing interests.

\section{Publisher's Note}

Springer Nature remains neutral with regard to jurisdictional claims in published maps and institutional affiliations.

\section{Author details}

'King Saud bin Abdulaziz University for Health Sciences, Riyadh, Kingdom of Saudi Arabia. ${ }^{2}$ Infectious Diseases, King Abdullah International Medical Research Center, Riyadh, Kingdom of Saudi Arabia. ${ }^{3}$ Infection Prevention and Control Department, King Abdulaziz Medical City (KAMC), Ministry of National Guard Health Affairs (MNGHA), P.O. Box 22490, Riyadh 11426, Kingdom of Saudi Arabia. ${ }^{4}$ Community Medicine Department, Faculty of Medicine, Mansoura University, Mansoura, Egypt. Intensive Care Department, KAMC, MNGHA, Riyadh, Saudi Arabia. ${ }^{6}$ Pathology and Laboratory Medicine Department, KAMC, MNGHA, Riyadh, Saudi Arabia. ${ }^{7}$ Cardiac Center \& Cardiac Sciences, KAMC, MNGHA, Riyadh, Saudi Arabia. ${ }^{8}$ Internal Medicine Department, Infectious Disease Division, KAMC, MNGHA, Riyadh, Saudi Arabia.

Received: 25 September 2018 Accepted: 11 December 2018 Published online: 21 December 2018

\section{References}

1. Leekha S, Terrell CL, Edson RS. General principles of antimicrobial therapy. Mayo Clin Proc. 2011;86(2):156-67.

2. Lode H. Safety and tolerability of commonly prescribed oral antibiotics for the treatment of respiratory tract infections. Am J Med. 2010;123(4 Suppl): S26-38.

3. Chang CY, Schiano TD. Review article: drug hepatotoxicity. Aliment Pharmacol Ther. 2007;25(10):1135-51.

4. Cotteret C, Vallieres E, Roy H, Ovetchkine P, Longtin J, Bussieres JF. Antibiotic consumption and bacterial sensitivity in a teaching hospital: a 5year study. Arch Pediatr. 2016;23(10):1040-9.

5. Schechner V, Temkin E, Harbarth S, Carmeli Y, Schwaber MJ. Epidemiological interpretation of studies examining the effect of antibiotic usage on resistance. Clin Microbiol Rev. 2013;26(2):289-307.

6. Lopez-Lozano JM, Monnet DL, Yague A, Burgos A, Gonzalo N, Campillos P, Saez M. Modelling and forecasting antimicrobial resistance and its dynamic relationship to antimicrobial use: a time series analysis. Int J Antimicrob Agents. 2000;14(1):21-31.

7. Goossens H, Ferech M, Vander Stichele R, Elseviers M. Outpatient antibiotic use in Europe and association with resistance: a cross-national database study. Lancet. 2005;365(9459):579-87.

8. Ventola CL. The antibiotic resistance crisis: part 1: causes and threats. P T. 2015;40(4):277-83

9. World Health Organization. Global action plan on antimicrobial resistance. Geneva; 2015. http://apps.who.int/iris/bitstream/10665/193736/1/ 9789241509763_eng.pdf?ua=1. Accessed 18 Dec 2018.

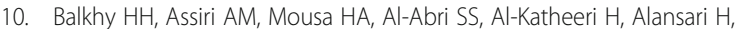
Abdulrazzaq NM, Aidara-Kane A, Pittet D. The strategic plan for combating antimicrobial resistance in gulf cooperation council states. J Infec Public Health. 2016;9(4):375-85.
11. Huttner B, Goossens H, Verheij T, Harbarth S. Characteristics and outcomes of public campaigns aimed at improving the use of antibiotics in outpatients in high-income countries. Lancet Infect Dis. 2010;10(1):17-31.

12. Bitterman R, Raz-Pasteur A, Azzam ZS, Karban A, Levy Y, Hayek T, Braun E, Oren I, Bar-Lavi Y, Kassis I, et al. Reduction of antibiotic consumption in Rambam health care campus - the role of an antibiotic stewardship program. Harefuah. 2017;156(9):573-7.

13. Johnson AP, Muller-Pebody B, Budd E, Ashiru-Oredope D, Ladenheim D, Hain D, Hope R, Bhattacharya A, Elgohari S, Guy R, et al. Improving feedback of surveillance data on antimicrobial consumption, resistance and stewardship in England: putting the data at your fingertips. J Antimicrob Chemother. 2017;72(4):953-6.

14. Al-Tawfiq JA. Changes in the pattern of hospital intravenous antimicrobial use in Saudi Arabia, 2006-2008. Ann Saudi Med. 2012;32(5):517-20.

15. Momattin H, Al-Ali AY, Mohammed K, Al-Tawfiq JA. Benchmarking of antibiotic usage: an adjustment to reflect antibiotic stewardship program outcome in a hospital in Saudi Arabia. J Infect Public Health. 2017.

16. World Health Organization. WHO collaborating Centre for Drug Statistics Methodology, guidelines for ATC classification and DDD assignment 2011. Oslo. 2010:2010

17. National Healthcare Safety Network (NHSN). Antimicrobial use and resistance (AUR) option. Patient Saf Component Manual. June 2011:2011.

18. Collado R, Losa JE, Alvaro EA, Toro P, Moreno L, Perez M. Measurement of antimicrobial consumption using DDD per 100 bed-days versus DDD per 100 discharges after the implementation of an antimicrobial stewardship program. Rev Esp Quimioter. 2015;28(6):317-21.

19. Fortin E, Quach C, Fontela PS, Buckeridge DL, Platt RW. A simulation study to assess indicators of antimicrobial use as predictors of resistance: does it matter which Indicator is used? PLoS One. 2015;10(12):e0145761.

20. Berrington A. Antimicrobial prescribing in hospitals: be careful what you measure. J Antimicrob Chemother. 2010;65(1):163-8.

21. Polk RE, Fox C, Mahoney A, Letcavage J, MacDougall C: Measurement of adult antibacterial drug use in 130 US hospitals: comparison of defined daily dose and days of therapy. Clin Infec Dis 2007; 44(5):664-670.

22. Marquet K, Liesenborgs A, Bergs J, Vleugels A, Claes N. Incidence and outcome of inappropriate in-hospital empiric antibiotics for severe infection: a systematic review and meta-analysis. Crit Care. 2015;19(1):63.

23. Youssif $E_{1}$ Aseeri M, Khoshhal $\mathrm{S}$. Retrospective evaluation of piperacillintazobactam, imipenem-cilastatin and meropenem used on surgical floors at a tertiary care hospital in Saudi Arabia. J Infect Public Health. 2017.

24. Balkhy HH, El-Saed A, Al Johani SM, Francis C, Al-Qahtani AA, Al-Ahdal MN, Altayeb HT, Arabi Y, Alothman A, Sallah M. The epidemiology of the first described carbapenem-resistant Klebsiella pneumoniae outbreak in a tertiary care hospital in Saudi Arabia: how far do we go? Eur J Clin Microbiol Infec Dis. 2012;31(8):1901-9.

25. Balkhy HH, El-Saed A, Maghraby R, Al-Dorzi HM, Khan R, Rishu AH, Arabi YM. Drug-resistant ventilator associated pneumonia in a tertiary care hospital in Saudi Arabia. Ann Thoracic Med. 2014;9(2):104-11.

26. Alotaibi FE, Bukhari EE, Al-Mohizea MM, Hafiz T, Essa EB, AlTokhais YI. Emergence of carbapenem-resistant Enterobacteriaceae isolated from patients in a university hospital in Saudi Arabia. Epidemiology, clinical profiles and outcomes. J Infect Public Health. 2017;10(5):667-73.

27. Zowawi HM, Sartor AL, Balkhy HH, Walsh TR, Al Johani SM, AlJindan RY, Alfaresi M, Ibrahim E, Al-Jardani A, Al-Abri S, et al. Molecular characterization of carbapenemase-producing Escherichia coli and Klebsiella pneumoniae in the countries of the Gulf cooperation council: dominance of OXA-48 and NDM producers. Antimicrob Agents Chemother. 2014;58(6):3085-90.

28. Garbati MA, Sakkijha H, Abushaheen A. Infections due to Carbapenem resistant Enterobacteriaceae among Saudi Arabian hospitalized patients: a matched case-control study. Biomed Res Int. 2016;2016:3961684.

29. Dumartin C, L'Heriteau F, Pefau M, Bertrand X, Jarno P, Boussat S, Angora P, Lacave L, Saby K, Savey A, et al. Antibiotic use in 530 French hospitals: results from a surveillance network at hospital and ward levels in 2007. J Antimicrob Chemother. 2010;65(9):2028-36.

30. National Nosocomial Infections Surveillance. (NNIS): NNIS system report, data summary from January 1992 through June 2004, issued October 2004. Am J Infect Control. 2004;32(8):470-85.

31. Meyer E, Schwab F, Gastmeier P, Rueden H, Daschner FD. Surveillance of antimicrobial use and antimicrobial resistance in German intensive care units (SARI): a summary of the data from 2001 through 2004. Infection. 2006;34(6):303-9. 
32. Rosenthal VD, Maki DG, Mehta A, Álvarez-Moreno C, Leblebicioglu H, Higuera F, Cuellar LE, Madani N, Mitrev Z, Dueñas L, et al. International nosocomial infection control consortium report, data summary for 20022007, issued January 2008. Am J Infect Control. 2008:36(9):627-37.

33. Walther SM, Erlandsson M, Burman LG, Cars O, Gill H, Hoffman M, Isaksson B, Kahlmeter G, Lindgren S, Nilsson L, et al. Antibiotic prescription practices, consumption and bacterial resistance in a cross section of Swedish intensive care units. Acta Anaesthesiol Scand. 2002;46(9):1075-81.

34. Vaccheri A, Silvani MC, Bersaglia L, Motola D, Strahinja P, Vargiu A, Poluzzi E, Montanaro N. A 3 year survey on the use of antibacterial agents in five Italian hospitals. J Antimicrob Chemother. 2008;61(4):953-8.

35. Dulhunty JM, Paterson D, Webb SA, Lipman J. Antimicrobial utilisation in 37 Australian and New Zealand intensive care units. Anaesth Intensive Care. 2011;39(2):231-7.

36. Polk RE, Hohmann SF, Medvedev S, Ibrahim O. Benchmarking risk-adjusted adult antibacterial drug use in 70 US academic medical center hospitals. Clin Infec Dis. 2011:53(11):1100-10.

37. Dalton BR, MacTavish SJ, Bresee LC, Rajapakse N, Vanderkooi O, Vayalumka J, Conly J. Antimicrobial use over a four-year period using days of therapy measurement at a Canadian pediatric acute care hospital. Can J Infect Dis Med Microbiol. 2015;26(5):253-8.

38. Cantey JB, Wozniak PS, Sanchez PJ. Prospective surveillance of antibiotic use in the neonatal intensive care unit: results from the SCOUT study. Pediatr Infect Dis J. 2015;34(3):267-72.

39. Candeloro CL, Kelly LM, Bohdanowicz E, Martin CM, Bombassaro AM. Antimicrobial use in a critical care unit: a prospective observational study. Int J Pharm Pract. 2012;20(3):164-71

40. Kaki R, Elligsen M, Walker S, Simor A, Palmay L, Daneman N. Impact of antimicrobial stewardship in critical care: a systematic review. J Antimicrob Chemother. 2011;66(6):1223-30.

Ready to submit your research? Choose BMC and benefit from:

- fast, convenient online submission

- thorough peer review by experienced researchers in your field

- rapid publication on acceptance

- support for research data, including large and complex data types

- gold Open Access which fosters wider collaboration and increased citations

- maximum visibility for your research: over $100 \mathrm{M}$ website views per year

At $\mathrm{BMC}$, research is always in progress.

Learn more biomedcentral.com/submissions 